\title{
Structural Characterization of Highly Corrosion-resistant Steel
}

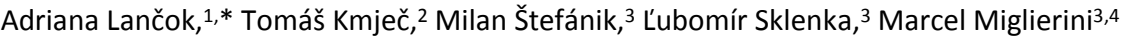

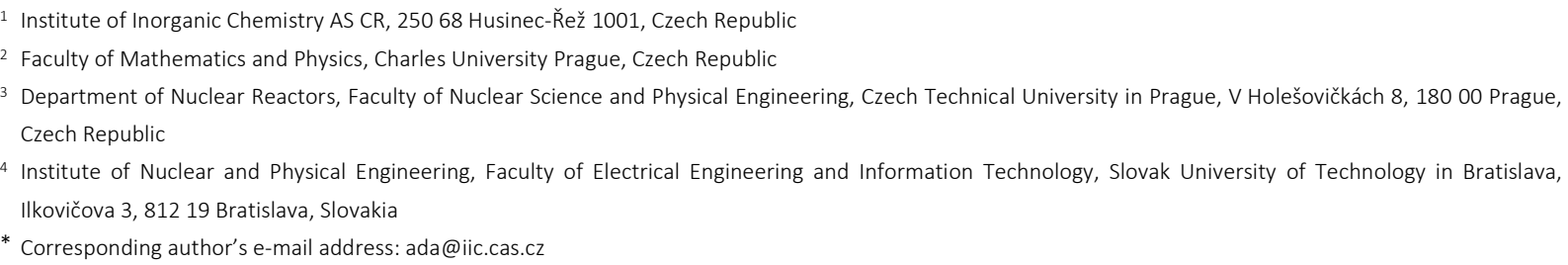

RECEIVED: November 23, 2015 * REVISED: February 5, 2016 * ACCEPTED: February 5, 2016

THIS PAPER IS DEDICATED TO DR. SVETOZAR MUSIĆ ON THE OCCASION OF HIS 70 TH BIRTHDAY

\begin{abstract}
Structural features of novel corrosion-resistant LC $200 \mathrm{~N}$ steel were investigated. Mössbauer spectrometry was chosen as a principal method of investigation. Surface as well as bulk properties were studied using Conversion Electron Mössbauer Spectrometry and transmission technique, respectively. Complex behaviour of magnetic and non-magnetic phases was identified in the samples by these two techniques. Chemical composition was checked by neutron activation analysis and X-ray fluorescence technique. Structural arrangement was studied by scanning electron microscopy with energy dispersive spectrometry and transmission electron microscopy. They unveiled regions with fairly varied $\mathrm{Cr}$ concentrations. Basing on a simple model of two different $\mathrm{Cr}$ concentrations, the relative areas of the Mössbauer sextets were modelled by a linear combination of two binomial distributions.
\end{abstract}

Keywords: Mössbauer spectroscopy, corrosion-resistant steel, LC200, CEMS.

\section{INTRODUCTION}

$\mathbf{N}$ EW materials are needed for industrial applications especially in the field of nuclear installations. Since the beginning of the $21^{\text {st }}$ century, a lot of new steels with improved performance parameters have appeared. Except for common mechanical testing method variety of structural and chemical analyses are employed for characterisation of these new materials. ${ }^{[1,2]}$

To understand the impact of diverse alloying elements and heat treatment upon the (micro) structural characteristics of such novel steels, Mössbauer spectrometry is employed as one of principal method of investigation. In the past, Mössbauer effect technique was shown to provide useful information related to thermal stability of metastable austenite in ledeburitic Cr-Mo-V tool steel.[2,3] They were prepared by rapid solidification of powder particles produced by nitrogen gas atomization. Morphological variations of the solidified microstructure were also examined using Mössbauer spectroscopy. ${ }^{[4]}$ These studies demonstrated the feasibility of Mössbauer spectroscopy for detailed investigations and its contribution to understand some problems of metallurgy.

Therefore, we use this particular technique as the main analytical tool in describing microstructural organization of recently introduced novel steel LC200N. ${ }^{[1]}$ High hardness and wear resistance of the LC200N steel suggest its possible promising applications in nuclear installations. Mössbauer spectrometry was chosen as a principal method of investigation.

Additional and very important information could be obtained from Mössbauer spectrometry about magnetic ordering of the steel. This information is crucial for applications in such equipment where high magnetic fields are applied (Nuclear Magnetic Resonance spectrometry - nonmagnetic materials, nuclear fusion, etc.) or where there is a 
need for measurement of weak magnetic fields (magnetometry).

In this study, we present investigations of a LC200N steel by Mössbauer spectrometry. Surface as well as bulk properties of steel sample were studied using CEMS (Conversion Electron Mössbauer Spectrometry) and transmission techniques. The former method is sensitive to the depths of about $200 \mathrm{~nm}$ and thus it is suitable for analysing (sub)surface regions.

Additional supporting information was obtained from other experimental methods: scanning electron microscopy (SEM), micro energy dispersion $\mathrm{X}$-ray fluorescence (micro ED XRF), X-ray diffraction (XRD), and neutron activation analysis (NAA).

\section{EXPERIMENTAL DETAILS}

Steel LC200N (by Zapp Materials Engineering, $\mathrm{GmbH}$ ) is highly nitrogenated and corrosion resistant alloyed tool steel produced by Pressurized Electric Slag Remelting technology (PESR), which increases purity and refines microstructure. Typical composition of LC200N is given in Tab.1. As a novel alloy it was introduced in late 2013. As compared to standard tool steels (like 1.2316, 1.4112 and 1.4125$)$ LC200N exhibits higher corrosion resistance and toughness as well as a higher tempering resistance up to $500{ }^{\circ} \mathrm{C}$ while it still retains its hardness of 58 $-60 \mathrm{HRc}$. Primary advantage is its excellent machinability and polishability as well as high dimensional stability after heat treatment.

\section{Sample Preparation}

LC200N steel annealed to low hardness was investigated. Disk-shaped samples were cut from rods with a diameter about $25 \mathrm{~mm}$ by brass wire electric discharge machining (wire-EDM). The thickness of the obtained disks was $\sim 0.5 \mathrm{~mm}$. Their surfaces were strongly contaminated by brass from the cutting wire. Chemical composition of the cut-off disks was analysed by micro ED XRF and NAA. Huge amount of $\mathrm{Cu}$ and $\mathrm{Zn}$ (brass 75/25) was confirmed (Figure 1).

In order to remove the surface contamination as well as to thin the disks to suitable dimensions (thickness) for transmission Mössbauer spectrometry, the samples were ground by SiC abrasive papers ( $240-2000$ grid) under water. When a final thickness from 50 to $100 \mu \mathrm{m}$ was reached, they were further polished by diamond paste $1.6 \mu \mathrm{m}$. An ultimate surface treatment with Wenol ${ }^{\circledR}$ Metal Polish paste has resulted in a mirror-like surface.

Powder ground off from the samples during the thinning process was collected from the water bath separately for each specimen by permanent magnet or using paper filter to avoid the influence of magnetic field on the steel particles. Some powder was contaminated by CuZn especially when it was collected at the beginning of the thinning process. Later on, when the brass containing surface regions were completely removed from the polished disks, pure steel powder was obtained. Powder samples contained $\mathrm{SiC}$ and $\mathrm{CaCO}_{3}$ particles from abrasive layers of the paper. Pure abrasive material was separated from abrasive paper for comparison.

The chemical composition of the alloy and its homogeneity was checked by micro ED XRF spectrometer EAGLE III $\mu$ Probe $(40 \mathrm{kV})$. Neutron irradiation of the samples for NAA analysis was carried out in a school nuclear reactor VR-1.

Mössbauer spectra were acquired in CEMS and transmission mode using a conventional constant acceleration-type spectrometer equipped with a ${ }^{57} \mathrm{Co}(\mathrm{Rh})$ source. Calibration of the velocity scale was performed with $\alpha-\mathrm{Fe}$ and isomer shifts are given with respect to its room temperature Mössbauer spectrum. All spectra were evaluated using the program CONFIT. ${ }^{[5]}$

\section{RESULTS AND DISCUSSION}

Micro ED XRF spectra measurements were performed upon brass-free surfaces of disk samples. The resulting chemical composition of steel was calculated and it is presented in Tab. 1. The calculated concentrations from Tab. 1 are in good agreement with the values published in the factory steel characterization data table. ${ }^{[1]}$

The results of micro ED XRF chemical analyses of brasscontaminated and ground surfaces of the sample are shown by their corresponding spectra in Figure 1. As it can be seen, no brass contamination was detected at the polished surface.

Using SEM in BSE (backscattered electrons) mode two different areas are distinguished in the investigated material as demonstrated in Figure 2. Matrix material is light grey and it is filled with dark (i.e. with lower atomic number - lighter) particles. The concentration of $\mathrm{Cr}$ and $\mathrm{Fe}$ is strongly different in matrix material and in dark ( $\mathrm{Cr}$-rich) particles. The concentration of chromium in matrix material is $15 \pm 4$ at. \% and it is close to the producers data. In the $\mathrm{Cr}$-rich particles (precipitates) its content is about $50 \pm 10$ at. \%.

In the powder sample, ground off from steel disk during polishing, additional particles with sharp contours of grains were found. They originated from the grounding process and contained $\mathrm{Si}$ and $\mathrm{C}$ (carborundum - see Figure 2). The typical size of steel particles in powder samples is between $0.5-10 \mu \mathrm{m}$. The particles are strongly distorted by grinding.

Neutron activation analysis was done on two samples: the first sample was part of the disk with a brass-contaminated surface ( $\mathrm{X}$ signed fields in Tab. 2 ) and the second one was the same material with polished brass-free surfaces. 
Phase composition of the disk and powder samples was determined by XRD. The information depth is from $\sim 4$ to $\sim 13 \mu \mathrm{m}$ for Co $\mathrm{K}_{\square}$ line. We have identified several phases in the bulk material of the disk. The content of ferrite, $\mathrm{CrC}$, and $\mathrm{CrCN}$ is about $70 \%, 10 \%$, and $20 \%$, respectively. Similar composition was detected in the powder sample. In addition the carborundum $(\mathrm{SiC})$ from the polish process and traces of brass (CuZn) were detected here as impurities.

In the fitting procedure of the Mössbauer spectra shown in Figure 3 were took into consideration the concept of binomial distributions as described for example in Ref. [6]. Nevertheless, due to complex nature of our samples, which contain at least two regions with notably different amounts of $\mathrm{Cr}$ (in addition to other alloying element), we have considered only the first nearest neighbour (n.n.) shell. Even then, the obtained hyperfine field values as well as their changes for different number of n.n. slightly differ

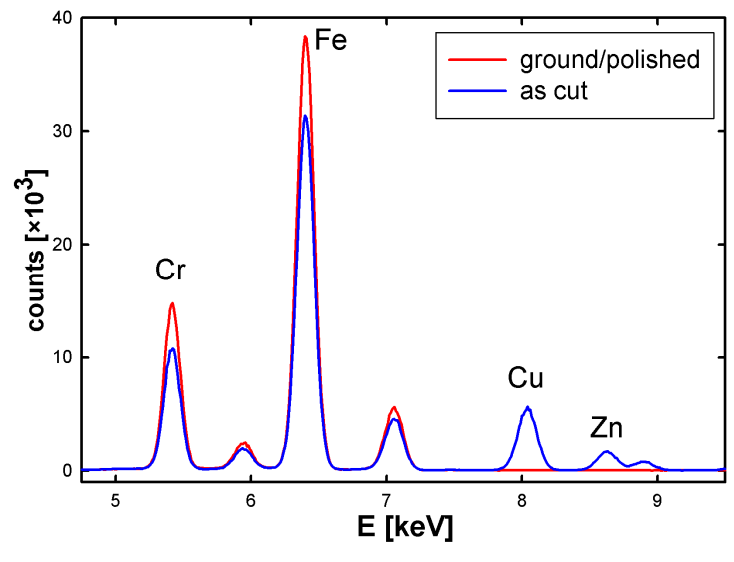

Figure 1. ED XRF spectra: red line corresponds to a spectrum from the primary (as cut) surface with brass contamination, blue line spectrum represents the polished surface.

Table 1. The chemical composition of the sample.

\begin{tabular}{|c|c|c|c|c|c|c|c|c|c|c|c|c|}
\hline Element & $\mathrm{Al}$ & $\mathrm{Si}$ & $P$ & V & N & C & $\mathrm{Cr}$ & $\mathrm{Mn}$ & $\mathrm{Fe}$ & $\mathrm{Ni}$ & $\mathrm{Cu}$ & Mo \\
\hline $\begin{array}{c}\text { Declared } \\
\text { concentration / \% }\end{array}$ & & 1.0 & & & $0.3-0.5$ & $0.25-0.35$ & $14-16$ & 1.0 & $75.0-80.0$ & 0.5 & & $0.85-1.10$ \\
\hline $\begin{array}{c}\text { Mass } \\
\text { concentration / \% }\end{array}$ & 0.7 & 1.0 & 0.2 & 0.13 & & & 16.1 & 0.8 & 79.4 & 0.2 & 0.1 & 1.4 \\
\hline $\begin{array}{c}\text { Atomic } \\
\text { concentration / \% }\end{array}$ & 1.4 & 2.0 & 0.3 & 0.1 & & & 16.9 & 0.8 & 77.5 & 0.2 & 0.1 & 0.8 \\
\hline
\end{tabular}
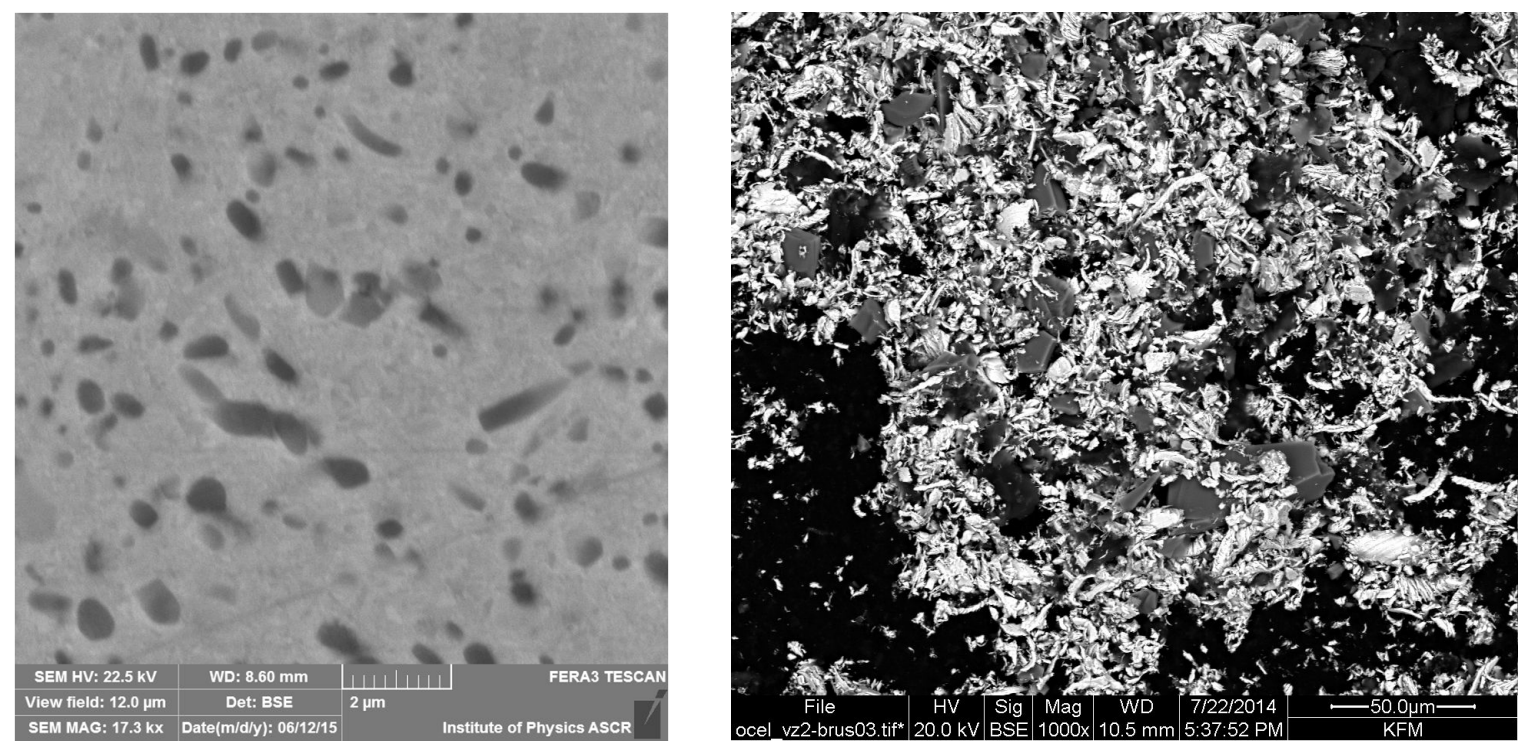

Figure 2. SEM BSE images: left - polished surface of the disk (light grey regions represent matrix with $15 \% \mathrm{Cr}$, dark grey ovals are particles containing $\sim 50 \% \mathrm{Cr}$ ), right - powder sample ground off from the disk (dark grey particles with sharp contours are grains of $\mathrm{SiC}$ ). 
from those reported in the literature. We assume that this is caused by the complex alloy's composition while the previous model studies took investigated pure $\mathrm{Fe}-\mathrm{Cr}$ systems. Contribution of the second n.n. shell in the fitting provided even higher deviations of the hyperfine field values as compared with a pure Fe-Cr system and that is why we have abandoned this (quite complicated) fitting approach. It is also noteworthy that the primary goal of the present study is mutual comparison of the spectral parameters obtained from the same alloy that is in different forms (foil versus powder) and using different techniques (transmission geometry versus CEMS).

With the maximum number of $n$. $n$. being eight, the Mössbauer spectra in Figure 3 were refined with eight sextets
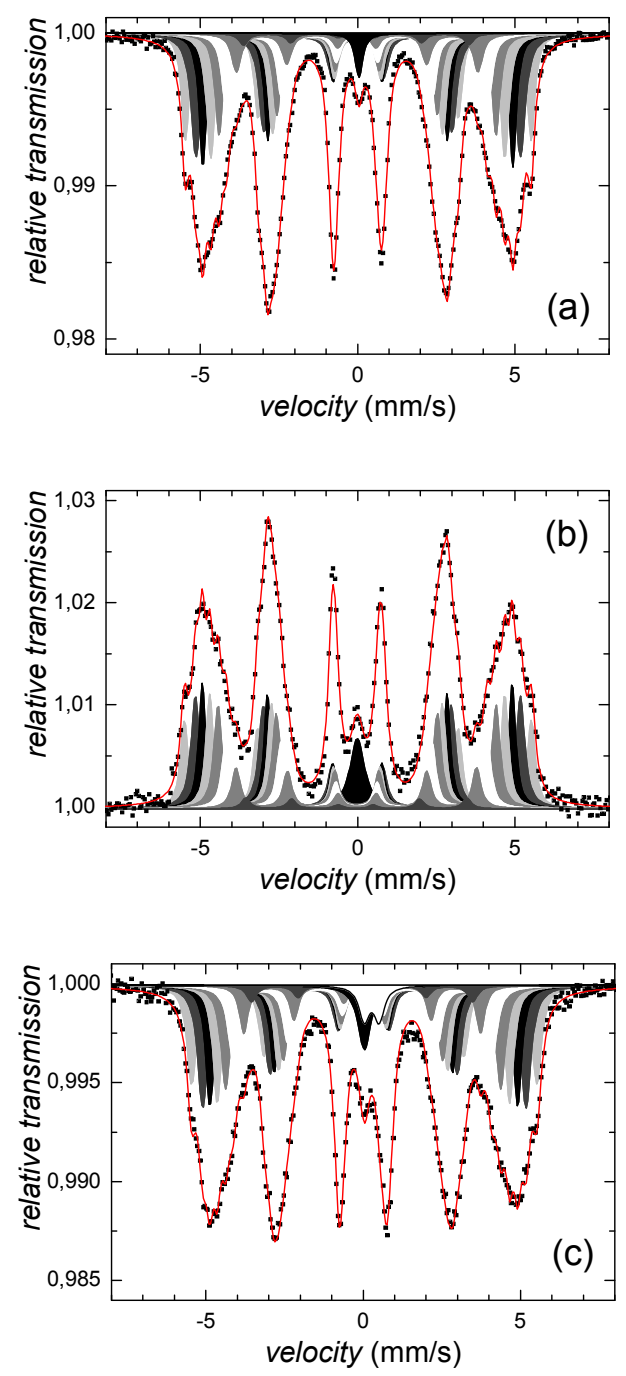

Figure 3. Mössbauer spectra of the disk recorded in transmission (a) and CEMS (b) modes, transmission Mössbauer spectrum of the powder sample (c). Individual spectral components are plotted in shades of grey.
Table 2. Results from neutron activation analysis.

\begin{tabular}{|c|c|c|c|c|c|}
\hline & $\begin{array}{c}\text { RA- } \\
\text { nuclide }\end{array}$ & $T_{1 / 2}$ & $\begin{array}{l}\text { As cut } \\
\text { sample } \\
\text { (with } \\
\text { CuZn) }\end{array}$ & $\begin{array}{l}\text { Polished } \\
\text { sample }\end{array}$ & Reaction \\
\hline 1 & ${ }^{24} \mathrm{Na}$ & $15 \mathrm{~h}$ & $X^{(b)}$ & & ${ }^{23} \mathrm{Na}(\mathrm{n}, \mathrm{g})^{24} \mathrm{Na}$ \\
\hline 2 & ${ }^{64} \mathrm{Cu}$ & $12,7 \mathrm{~h}$ & $x$ & & ${ }^{63} \mathrm{Cu}(\mathrm{n}, \mathrm{g}){ }^{64} \mathrm{Cu}$ \\
\hline 3 & ${ }^{76} \mathrm{As}$ & $1,1 \mathrm{~d}$ & $x$ & & ${ }^{75} \mathrm{As}(\mathrm{n}, \mathrm{g}){ }^{76} \mathrm{As}$ \\
\hline 4 & ${ }^{69 m} \mathrm{Zn}$ & $13,8 \mathrm{~h}$ & $x$ & & ${ }^{68} \mathrm{Zn}(\mathrm{n}, \mathrm{g})^{69 \mathrm{~m} \mathrm{Zn}}$ \\
\hline 5 & ${ }^{51} \mathrm{Cr}$ & $27,7 d$ & $x$ & $x$ & ${ }^{50} \mathrm{Cr}(\mathrm{n}, \mathrm{g})^{51} \mathrm{Cr}$ \\
\hline 6 & ${ }^{56} \mathrm{Mn}^{(\mathrm{a})}$ & $2,6 \mathrm{~h}$ & $x$ & $x$ & ${ }^{56} \mathrm{Fe}(\mathrm{n}, \mathrm{p})^{56} \mathrm{Mn}$ \\
\hline 7 & ${ }^{54} \mathrm{Mn}$ & $312 \mathrm{~d}$ & $x$ & $x$ & ${ }^{54} \mathrm{Fe}(\mathrm{n}, \mathrm{p})^{54} \mathrm{Mn}$ \\
\hline 8 & ${ }^{59} \mathrm{Fe}$ & $44,5 d$ & $x$ & $x$ & ${ }^{58} \mathrm{Fe}(\mathrm{n}, \mathrm{g})^{59} \mathrm{Fe}$ \\
\hline 9 & ${ }^{58} \mathrm{Co}$ & $70,8 \mathrm{~d}$ & & $x$ & ${ }^{58} \mathrm{Ni}(\mathrm{n}, \mathrm{p})^{58} \mathrm{Co}$ \\
\hline 10 & ${ }^{60} \mathrm{Co}$ & $5,2 y$ & $x$ & $x$ & ${ }^{60} \mathrm{Ni}(\mathrm{n}, \mathrm{p})^{60} \mathrm{Co}$ \\
\hline 11 & ${ }_{99}^{99}$ & $69,5 \mathrm{~h}$ & $x$ & $x$ & ${ }^{98} \mathrm{Mo}(\mathrm{n}, \mathrm{g})^{99} \mathrm{Mo}$ \\
\hline 12 & ${ }^{93 \mathrm{~m}} \mathrm{Mo}$ & $6,9 \mathrm{~h}$ & & $x$ & ${ }^{92} \mathrm{Mo}(\mathrm{n}, \mathrm{g})^{93 \mathrm{~m}} \mathrm{Mo}$ \\
\hline 13 & ${ }^{187} \mathrm{~W}$ & $23,7 \mathrm{~h}$ & $x$ & $x$ & ${ }^{186} W(n, g)^{197} W$ \\
\hline
\end{tabular}

and a singlet (plus doublet). Sextets represent magnetically ordered Fe atoms that have different numbers of $\mathrm{Cr}$ as their nearest neighbours (n.n.) in bcc crystallographic positions. Assuming random distribution of $\mathrm{Cr}$ and $\mathrm{Fe}$ atoms over the lattice sites, the probabilities $P_{n}(x)$ of occupation of the sites by $n \mathrm{Cr}$ n.n.'s follow then from a binomial distribution:

$$
P_{n}(x)=\frac{8 !}{n !(8-n) !} \cdot x^{n} \cdot(1-x)^{8-n}
$$

where $n$ is the number of $\mathrm{Cr}$ n.n. ( $n=0$ through 8 ) and $x$ is the $\mathrm{Cr}$ concentration. One binomial distribution is calculated for bulk material with concentration of $\mathrm{Cr} \sim 15 \%$ and the second one for $\mathrm{Cr}$-rich precipitates with $\mathrm{Cr} \sim 50 \%$. Relative intensities of the sextets $I_{n}$ are assumed as a linear combination of these two binomial distributions:

$$
I_{n}=c_{15} \cdot P_{n}(15)+C_{50} \cdot P_{n}(50)
$$

where $c_{15}$ and $c_{50}$ represent the relative amounts of regions with $\mathrm{Cr}$ concentration of $15 \%$ and $50 \%$, respectively.

The experimental Mössbauer spectra were fitted by 8 sextets ( $\mathrm{S} 1$ to $\mathrm{S} 8$ ) for magnetic ordered ferrite phase (see Figure 3). We ascribed the sextets $\mathrm{S} 1-\mathrm{S} 8$ to Fe-atoms with 0 to $7 \mathrm{Cr}$ atoms in Fe n.n.. The component corresponding to eight 

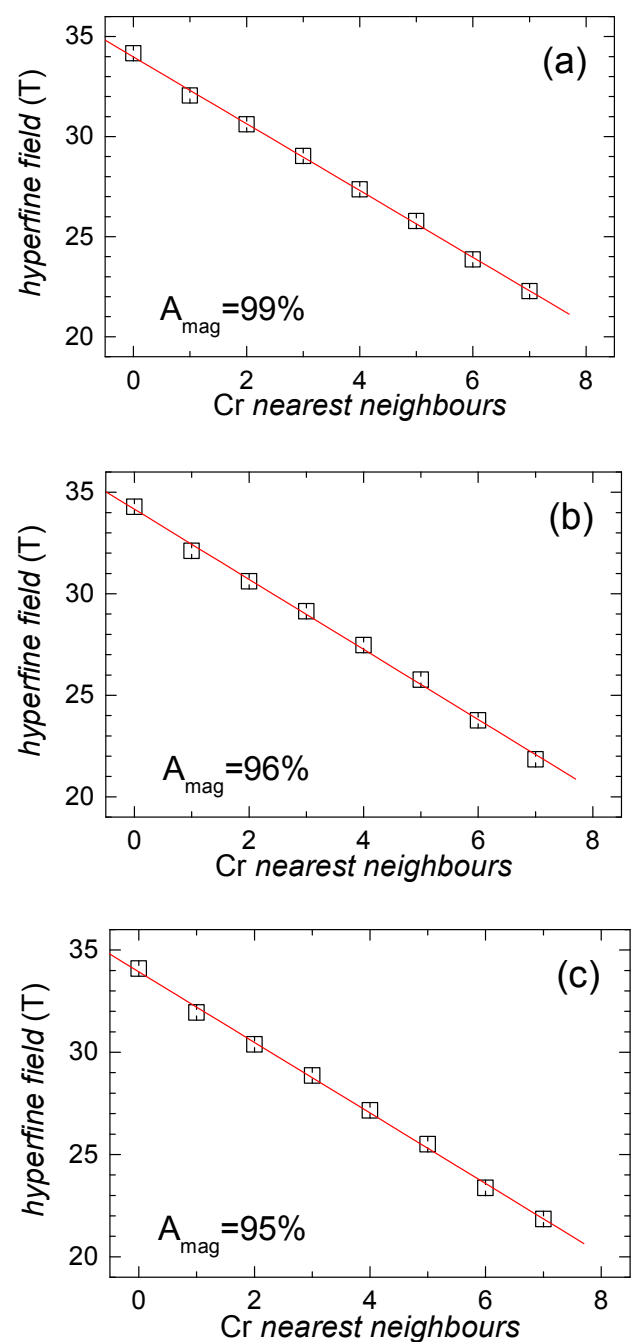

Figure 4. Hyperfine fields plotted as a function of the number of $\mathrm{Cr}$ n.n. as obtained from the evaluation of the Mössbauer spectra of the disk sample measured in transmission (a) and CEMS (b) modes and from the transmission Mössbauer spectrum of the powder sample (c).

$\mathrm{Cr}$ n.n. may form a part of the detected singlet whose spectral line is overlaid with that of non-magnetic austenite. Isomer shift of this singlet ranges from $-0.008 \pm 0.024 \mathrm{~mm} / \mathrm{s}$ to $0.040 \pm 0.024 \mathrm{~mm} / \mathrm{s}$ and their line widths are between 0.50 and $0.58 \mathrm{~mm} / \mathrm{s}$. Nevertheless, because of possible overlap of these two spectral components and their overall relative fraction of $\sim 2 \%$ it is practically impossible to distinguish one from the other. A weak doublet in the powder sample spectrum is ascribed to traces of unidentified non-magnetic iron phase originated from the grinding process.

Dependencies of hyperfine fields $B_{\mathrm{hf}}$ in Figure 4 are fitted using the formula $B_{\mathrm{hf}}=a-b \cdot n(\mathrm{Cr}$ n.n.) with $a$
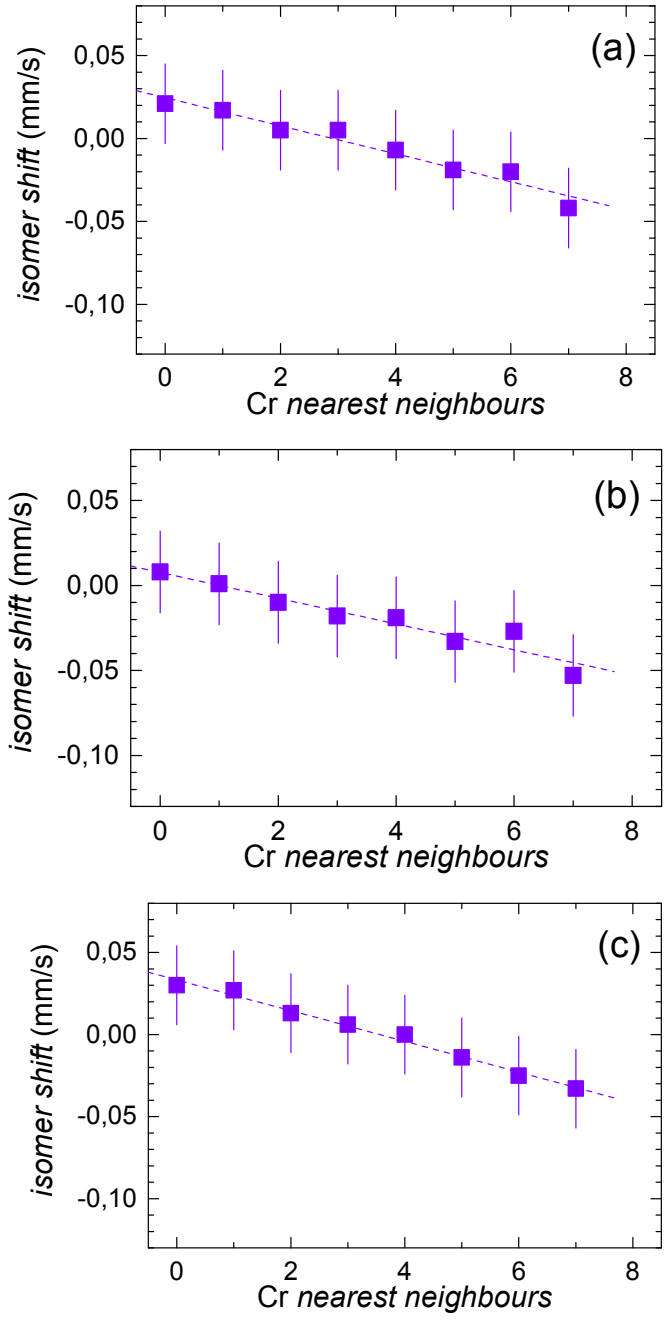

Figure 5. Isomer shift of the sextet spectral components plotted against the number of $\mathrm{Cr}$ n.n. as obtained from the evaluation of the Mössbauer spectra of the disk sample measured in transmission (a) and CEMS (b) modes and from the transmission Mössbauer spectrum of the powder sample (c).

equals $\sim 34 \mathrm{~T}$ and $b \sim 0.17 \mathrm{~T} /(\mathrm{Cr}$ n.n.). Both the disk and the powder samples from this steel contained mostly magnetically ordered ferritic phases $\left(A_{\mathrm{mag}} \sim 99 \%\right.$ for the disk and $A_{\text {mag }} \sim 95 \%$ for the powder sample) with small amount of non-magnetic austenite phase. Surface layer of this material measured by CEMS has very similar composition ( $A_{\mathrm{mag}} \sim 96 \%$ ).

Figure 5 shows linearly decreasing values of isomer shift with increasing number of $\mathrm{Cr}$ n.n. for the magnetic spectral components in all measured Mössbauer spectra. Slight differences were revealed, however, in the slopes of the linear fits. The values of quadrupole shift are close to zero for all sextets. 
We have used 8 sextets during fitting of the experimentally obtained Mössbauer spectra. Their resulting relative contributions (areas) are depicted in Figure 6 by solid black circles. As it was described above, two regions with notably different $\mathrm{Cr}$ concentrations were identified by SEM. Consequently, their corresponding binomial distributions were calculated and they are plotted in Figure 6, too. The first
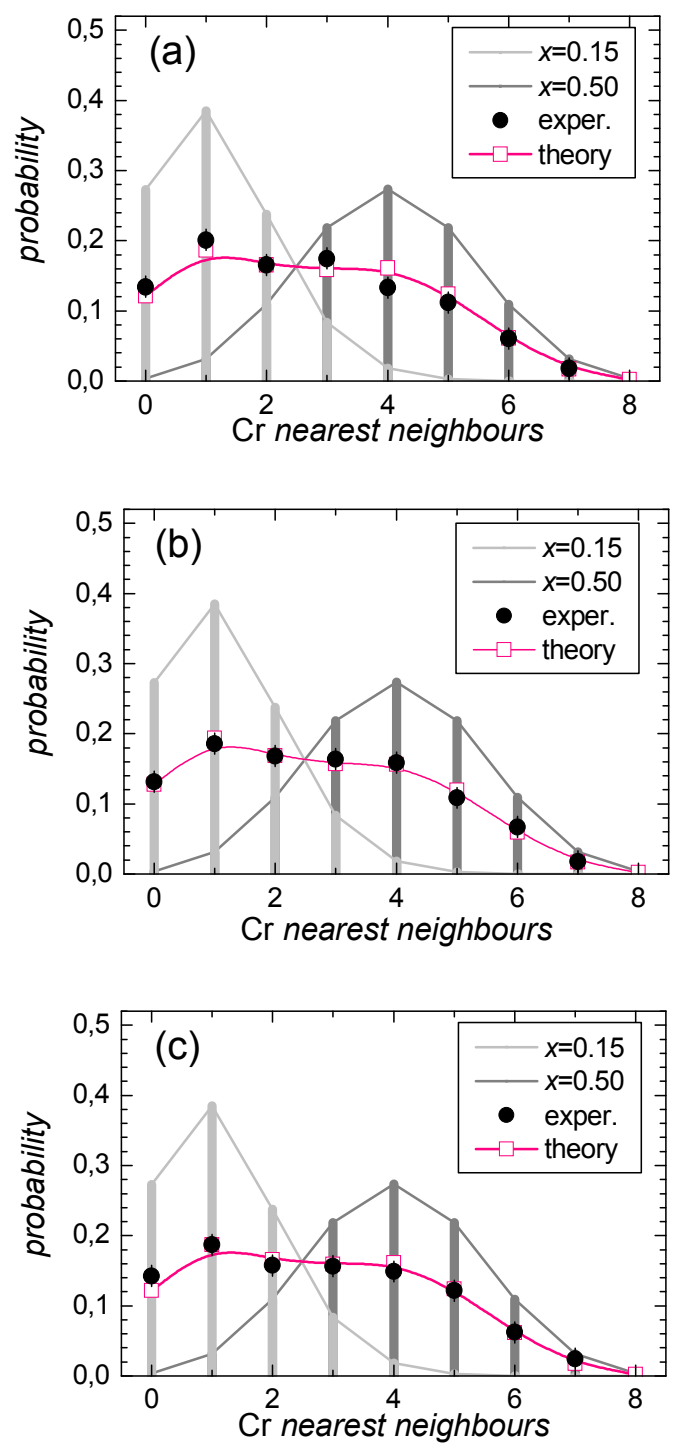

Figure 6. Probabilities of the number of $\mathrm{Cr}$ n.n. as obtained from the evaluation of the Mössbauer spectra of the disk recorded in transmission (a) and CEMS (b) mode and from the transmission Mössbauer spectrum of the powder sample (c). Values from experiment (black solid circles) are fitted to those (open pink squares interconnected with solid lines) from linear combination of binomial distributions of n.n. probabilities calculated for $\mathrm{Cr}$ regions with $x=0.15$ (light grey) and $x=0.50$ (dark grey). binomial distribution, which was calculated for concentration of $\mathrm{Cr}=15 \%$, is shown by light grey lines and columns. The dark grey lines and columns belong to the second binomial distribution for $\mathrm{Cr}$-rich precipitates with $\mathrm{Cr} \sim 50 \%$. A linear combination of these two binomial distributions was implicitly assumed during evaluation of the experimental spectra. After obtaining relative contributions of the individual sextets (the solid black circles) these were subsequently fitted to the linear combination of the two binomial distributions according to Eq. 2. Pink symbols and lines in Figure 6 represent the results of these subsequent fits. Quantitative evaluation shows that the steel displays regions with $c_{15}: c_{50}=$ $56: 44$ for the disk and the powder samples (measured in transmission geometry) and a similar ratio of $54: 46$ for the surface of the disk sample (CEMS). Taking into account an estimated range of experimental errors in the determination of spectral line areas of $\pm 1.5 \%$, all ratios can be considered equal. This is not surprising as we have investigated the same material though using different approaches. It is, however, necessary to remark that these results are based on the assumption of random distribution of $\mathrm{Fe}$ and $\mathrm{Cr}$ atoms over the lattice sites that are located in two regions with remarkably distinct $\mathrm{Cr}$ content. In particular, segregation of a $\mathrm{Cr}$ rich phase as identified by SEM (Figure 2) was unexpected.

\section{CONCLUSIONS}

Structural and magnetic properties of the LC $200 \mathrm{~N}$ steel reflected in the hyperfine interactions were investigated by Mössbauer spectroscopy with ${ }^{57} \mathrm{Fe}$ nuclei as probes. It was possible to identify several phases, two magnetically ordered ferrite phases and small amount of nonmagnetic phase (austenite). Magnetic phases exhibit rather complex behaviour due to varying number of chromium atoms in the first n.n. of the resonance Fe atoms. Taking into account the results of other physical methods, two structurally distinct regions were revealed in the material with significantly different concentrations of $\mathrm{Cr}$. Consequently, a model for the evaluation of Mössbauer spectra was proposed and successfully applied.

Feasibility of the above mentioned model is reflected in the dependences of the derived hyperfine spectral parameters, including isomer shift, quadrupole splitting, and hyperfine magnetic field, with an expected number of $\mathrm{Cr}$ n.n. The results obtained indicate that under the assumption of random distribution of $\mathrm{Fe}$ and $\mathrm{Cr}$ atoms the investigated steel would displayed regions with the relative concentrations of $\sim 15 \% \mathrm{Cr}$ and $\sim 50 \% \mathrm{Cr}$ in an average ratio of about $55: 45$.

Acknowledgment. This work was supported by the research grant GAČR 14-12449S and project UK SVV-2015-260213. The authors would like to thank Dr. Petr Bezdička for XRD measurement and analyses. 


\section{REFERENCES}

[1] http://www.bolzano.cz/assets/files/LC200N-smechanickymi-hodnotami.pdf

[2] P. Grgač, R. Moravčík, M. Kusý, I. Tóth, M. Miglierini, E. Illeková, Mater. Sci. Eng. A 2004, 375-377, 581.

[3] P. Grgač, M. Kusý, L. Čaplovič, M. Miglierini, T. Kaňuch,
K. Vitázek, Mater. Sci. Eng. A 2007, 449-451, 1029.

[4] M. Kusý, P. Grgač, M. Behúlová, A. Výrostková, M. Miglierini, Mater. Sci. Eng. A 2004, 375-377, 599.

[5] T. Žák, Y. Jirásková, Surf. Interface Anal. 2006, 38, 710.

[6] S. M. Dubiel, J. Cieslak, H. Reuther, J. Nucl. Mater. 2013, 434:1-3, 235. 